\title{
Influence of atmospheric modes on coastal upwelling along the western coast of the Iberian Peninsula, 1985 to 2005
}

\author{
M. deCastro*, M. Gómez-Gesteira, M. N. Lorenzo, I. Alvarez, A. J. C. Crespo \\ Grupo de Física de la Atmósfera y del Océano, Facultad de Ciencias, Universidad de Vigo, 32004 Ourense, Spain
}

\begin{abstract}
Using night-time weekly sea surface temperatures (1985 to 2005), we analysed how several European regional patterns of atmospheric variation influenced coastal upwelling along the western coast of the Iberian Peninsula. The regional patterns of atmospheric variation considered were: the North Atlantic Oscillation, the East Atlantic pattern, the Scandinavia pattern, the East Atlantic/Western Russia pattern and the Europe Polar/Eurasia pattern (NAO, EA, SCA, EA/WR and POL, respectively). The upwelling index along the entire coast was calculated as the difference between coastal and oceanic sea surface temperature at the same latitude for 25 locations distributed from 37 to $43^{\circ} \mathrm{N}$. Relationships with atmospheric circulation modes during the upwelling season (July to October) show that the main upwelling anomaly variability can be explained in terms of the EA, showing a significant negative correlation along the entire western coast. The NAO pattern is the second most influential atmospheric mode, with influence on the upwelling index showing a significant positive correlation only between 38 and $41^{\circ} \mathrm{N}$.
\end{abstract}

KEY WORDS: Coastal upwelling - Sea surface temperature $\cdot$ Satellite data $\cdot$ Atmospheric modes · Western coast of the Iberian Peninsula

Resale or republication not permitted without written consent of the publisher

\section{INTRODUCTION}

The western coast of the Iberian Peninsula (IP) is the northern boundary of the Canary Upwelling Ecosystem (CUE), which is 1 of the 4 major eastern boundary upwelling regions in the world (Di Lorenzo 2003, Pelegri et al. 2005). Seasonal upwelling activity along the western coast of the IP occurs during the summer months as a result of persistent northerly wind forcing (Nykjaer \& Van Camp 1994, Gómez-Gesteira et al. 2006). Generally, northerly along shore winds produce surface Ekman transport offshore. The divergent flow at the surface is compensated by an onshore flow below that brings colder and nutrient-rich waters to the surface along the coast. The CUE has important biological implications, since the primary production in the estuaries and in the adjacent platform is likely controlled by the upwelling phenomenon (Shannon et al. 2003). This fact makes the CUE a productive ecosystem from the point of view of primary production and fisheries, with important socio-economic impacts in the neighbouring regions.

The variability of this upwelling system has been studied on scales from synoptic to seasonal (Torres et al. 2003, Alvarez et al. 2005). It has also been studied on longer time scales (decadal) (Blanton et al. 1987), but to a lesser extent, due to the lack of sufficiently long, continuous time series. Most of the upwelling variability studies on decadal scales are related to upwelling indices (offshore Ekman transport) calculated from sparse local wind data without a coherent spatio-temporal pattern. Recently, the upwelling along the Galician coast (northwest of the IP) was analyzed by means of coherent spatio-temporal wind data obtained from the QuikScat satellite, from 1999 to 2004 , with a spatial resolution of $0.25 \times 0.25^{\circ}$ (Torres et al. 2003), and data obtained from the Regional Weather Forecast Agency (METEOGALICIA), for the period from 2001 to 2004, with a horizontal grid mesh of $10 \mathrm{~km}$ (Gómez-Gesteira et al. 2006). Upwelling 
indices can also be obtained from the National Centre of Atmospheric Research/National Centre for Environmental Prediction (NCEP/NCAR) Reanalysis Data Archive from 1948 onwards (which has global coverage, but a spatial resolution of only $2.5 \times 2.5^{\circ}$ ). Upwelling indices with a finer resolution $\left(1 \times 1^{\circ}\right)$ and global coverage can also be obtained from the Pacific Fisheries Environmental Laboratory (www.pfeg.noaa. gov/products/las/docs/global_upwell.html), but in this case from 1967 onwards. A suitable data set to analyze upwelling variability over long periods of time is satellite-derived, sea surface temperature (SST) observations, because of their good time-space resolution and global coverage. The lowering of SST following coastal upwelling may be as large as 6 to $8^{\circ} \mathrm{C}$, making the satellite data particularly useful in the study of the large-scale distribution of coastal upwelling. SST is one of the ocean-surface parameters that are relatively easy to obtain from satellite data. Satellite-derived images of SSTs have been used largely to analyze synoptic upwelling processes and the annual variations in SST across the world (e.g. Tang et al. 2004 in the Taiwan Strait; Zavala-Hidalgo et al. 2006 in the Gulf of Mexico). In particular, satellite SST have been widely used in previous studies of the CUE, which were limited to the internal, spatially fine structure of upwelling (e.g. fronts, eddies, filaments) and its fluctuations from synoptic to inter-annual time scales (e.g. Nykjaer \& Van Camp 1994) because of the short time series data available. Recently, Santos et al. (2005) confirmed the validity of using satellite-derived SST data to analyze the spatio-temporal patterns of decadal variability of the CUE and their impact upon the ecosystem. A similar SST data set was used to study the seasonal and inter-annual variability of the Black Sea and to compare the mean SST fields obtained with known climatic distributions (Ginzburg et al. 2004).

Teleconnection patterns reflect large-scale changes in the atmospheric wave and jet stream patterns, which can influence temperature, rainfall, storm tracks, and/or jet stream location/intensity over vast areas. Thus, they are often the phenomenon responsible for abnormal weather patterns occurring simultaneously over seemingly vast distances. Previous studies (Rodríguez-Puebla et al. 1998, Lorenzo \& Taboada 2005, deCastro et al. 2006) have considered that the most representative regional patterns of atmospheric variation in the Northern Hemisphere, with some influence on the eastern North Atlantic region, are: the North Atlantic Oscillation (NAO), the East Atlantic pattern (EA), the Scandinavia pattern (SCA), the East Atlantic/Western Russia pattern (EA/WR) and the Europe Polar/Eurasia pattern (POL). These atmospheric circulation patterns are indicators of large-scale decadal change and play a key role in long-term vari- ability of winds across the North Atlantic affecting coastal upwelling intensity.

The NAO consists of a north-south dipole of geopotential anomalies with one centre located over Greenland and the other one spanning between 35 and $40^{\circ} \mathrm{N}$ in the central North Atlantic. A positive phase in the NAO index represents an increase in the pressure differences, resulting in an increase in frequency and strength of winter storms crossing the Atlantic Ocean that typically take a more northerly track. This causes warm and wet winters in the northern part of Europe and drier than normal winters in the south. The negative phase represents a reduced pressure gradient resulting in fewer and weaker winter storms crossing Europe, which travel on a more west-east pathway. This brings moist air into the Mediterranean and causes drier winters in the northern part of Europe. Research has identified the NAO index as the local manifestation of the more global pattern of the Arctic Oscillation (AO) during the winter (DJF) (Thompson \& Wallace 2000). It has been found that the NAO can be predicted with reasonable skill from North Atlantic SST anomalies (SSTA) averaged over several prior months (Czaja \& Marshall 2002, Bojariu \& Gimeno 2003). The relationship between the NAO index and winter surface temperatures, especially over Europe, has been extensively recorded (Kapala et al. 1998). Slonosky \& Yiou (2002) analyzed the degree to which the NAO index reflects the zonal and meridional flow and its influence on SST by means of a near sea surface data set for the years from 1856 to 2000. Although the NAO index has been the most commonly studied mode in the IP (Rodríguez-Puebla et al. 1998, 2001, Trigo et al. 2004, Santos et al. 2005), recent studies (deCastro et al. 2006, Lorenzo et al. in press) have shown the need to consider additional modes to explain the variable structure of winter rainfall and river flow in Galicia.

The EA pattern consists of a north-south dipole that spans the entire North Atlantic Ocean with centres near $55^{\circ} \mathrm{N}, 20$ to $35^{\circ} \mathrm{W}$ and 25 to $35^{\circ} \mathrm{N}, 0$ to $10^{\circ} \mathrm{W}$. It is the second prominent mode of low-frequency variability over the North Atlantic, and appears to be the leading mode in all months. The EA pattern is structurally similar to the NAO, but with the anomaly centres displaced south-eastward to the approximate nodal lines of the NAO pattern. For this reason, the EA pattern is often interpreted as a 'southward shifted' NAO pattern. However, the lower-latitude centre contains a strong subtropical link in association with modulations in the subtropical ridge intensity and location. This subtropical link makes the EA pattern distinct from its NAO counterpart. The positive phase of the EA is associated with above-average precipitation over northern Europe and Scandinavia and with below-average precipitation across southern Europe (Rodríguez-Puebla 
et al. 1998, 2001). On the other hand, the positive phase of the EA pattern is associated with aboveaverage surface temperatures in Europe. In particular in the northern part of the IP, the EA pattern is the most important variation explaining temperature variability (Saenz et al. 2001).

The SCA pattern (Barnston \& Livezey 1987) consists of a primary circulation centre over Scandinavia, with a weaker centre with the opposite sign over Western Europe. The positive phase of this pattern is associated with positive height anomalies, sometimes reflecting major blocking anticyclones over Scandinavia and western Russia.

The EA/WR pattern (Barnston \& Livezey 1987) is 1 of 3 prominent teleconnection patterns that affect Eurasia throughout the year. This pattern consists of 4 main anomaly centres. The positive phase is associated with positive height anomalies located over Europe and northern China and negative height anomalies located over the central North Atlantic and north of the Caspian Sea. The main precipitation departures associated with the positive phase of the EA/WR pattern reflect generally above-average precipitation in eastern China and below-average precipitation across central Europe.

The POL (Barnston \& Livezey 1987) consists of 1 centre over the polar region and centres of the opposite sign over Europe and north-eastern China. The positive phase of this pattern is associated with the presence of anomalies over western Europe blocking the passage of low pressure fronts to the north-western coast of the IP and causing drier than normal winters.

Several studies have indicated the influence of the main atmospheric circulation modes on the interannual precipitation variability and drought occurrence in Spain (Rodó et al. 1997, Rodríguez-Puebla et al. 1998, Pozo-Vázquez et al. 2005). In particular, many authors have pointed out that several atmospheric circulation patterns influence precipitation in the northwest part of the IP, but that no one pattern describes the bulk of the variability in precipitation over the region (Rodríguez-Puebla et al. 1998). Nevertheless, to the best of our knowledge, there has not been an analysis of the relationship between the regional atmospheric circulation modes and the upwelling variability along the western coast of the IP. However, Santos et al. (2005) do hypothesize about a link between low (high) phases of the NAO index with a warm (cold) SSTA at mid-latitudes of the CUE.

The aim of the present study is to analyze the relationship between the upwelling variability along the western coast of the IP and the most representative regional patterns of atmospheric variability in the Northern Hemisphere that have an influence upon the eastern North Atlantic region (NAO, EA, SCA, EA/WR and POL). This study was carried out during the upwelling season (July to October, JASO hereafter) from 1985 to 2005. The present study is structured as follows: In Section 2, we describe the oceanographic and atmospheric data sets and the processing carried out in the paper. In Section 3, the upwelling season is described by means of satellite-derived SST. In addition, we present correlations between atmospheric and upwelling indices, which were calculated for the entire coast to identify the atmospheric circulation patterns with the most influence on coastal upwelling variability. Correlations are physically interpreted by the following means: an analysis of extreme events, a sea level pressure (SLP) composite analysis and an analysis of zonal Ekman transport. Finally, summary and conclusions are presented in Section 4.

\section{DATA PROCESSING}

\subsection{Oceanographic data processing}

SST data were obtained from the NOAA/NASA Advanced Very High Resolution Radiometers (AVHRR) (http://poet.jpl.nasa.gov). Multi-channel sea surface temperatures (MCSST) have been computed from AVHRR radiances operational since 1981. A detailed evaluation of the calibration procedures for the NOAA AVHRR based on thermal vacuum test data was performed by researchers at the University of Miami (Brown et al. 1993). Moreover, an improved processing scheme has led to a more sensitive cloudclearing technique. The SST computation from AVHRR radiances is discussed in McClain et al. (1985). Briefly, the radioactive transfer theory is used to correct the atmosphere effects on observations using 'windows' of the electromagnetic spectrum, where little or no atmospheric absorption occurs. Channel radiances are transformed to units of temperature using the Planck function, and then compared to a priori temperatures measured at the surface. This comparison yields coefficients, which, when applied to the global AVHRR data, give estimates of surface temperature that have been nominally accurate to $0.3^{\circ} \mathrm{C}$. The Pathfinder SST data are available from 1985, and they are distributed in a variety of resolutions and temporal averages. Each data product is obtained as either an ascending (daytime) or descending (night-time) image. These data are produced as daily composites, which are defined as spatial bins of all temperature retrievals at a maximum resolution of $4 \mathrm{~km}$. From the daily products, $8 \mathrm{~d}$, monthly and yearly composites are formed.

In our study we chose a spatial resolution of $4 \mathrm{~km}$ and a temporal average of $8 \mathrm{~d}$ for the period from 1985 to 2005. We only considered the night-time image in 
order to avoid the solar heating effect. For our purposes, the area limited by 37 to $44^{\circ} \mathrm{N}, 8$ to $15^{\circ} \mathrm{W}$ was examined from the global data set (Fig. 1). First, SST data were averaged to a monthly time scale. Then, voids due to cloud coverage or other malfunctions were interpolated from nearest neighbours by means of a weighted (Gaussian) average. The process was iterated from an initial square box of $3 \times 3$ neighbours $(12 \times 12 \mathrm{~km})$ around the point until a maximum distance of $15 \times 15$ neighbours $(60 \times 60 \mathrm{~km})$ had been obtained. The process was automatically stopped when the number of neighbours with reliable values inside the box was $>5$.

The SST upwelling index (UI) was defined following Nykjaer \& Van Camp (1994) and Santos et al. (2005) as the SST difference between coastal $(20 \mathrm{~km}$ from the IP coast) and oceanic (500 km offshore) locations at the same latitude. Two discrete sets of points corresponding to 25 positions placed at 20 and $500 \mathrm{~km}$ from the coast, respectively, were generated (denoted as crosses in Fig. 1). Discretization effects were smoothed by calculating SST monthly values at each point as the average of its nearest neighbours at the same latitude. SST values at the point were considered together with its northern and southern neighbours (separated by $4 \mathrm{~km}$ in the original data set). The discrete series obtained ranges from 37 to $43^{\circ} \mathrm{N}$ in such a way that the distance between adjacent points is on the order of $18 \mathrm{~km}$. UI at each latitude was calculated subtracting equal-indexed points from both series. The high reso-

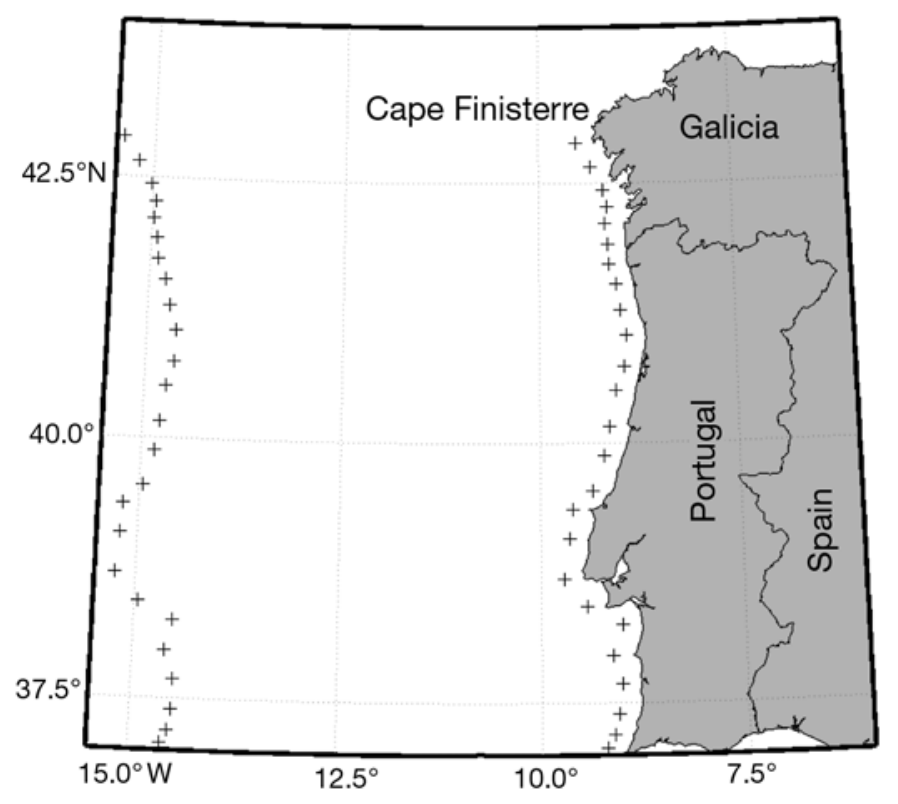

Fig. 1. Area under examination along the western coast of the Iberian Peninsula. Crosses: sites where sea surface temperature (SST) values were obtained $(20 \mathrm{~km}$ from coast and $500 \mathrm{~km}$ offshore) lution allowed the measuring of SST near the coast, which was crucial to determining the upwelling index as the temperature difference between the coast and ocean. The upwelling signature can be easily recognised by the sudden SST decrease near the coast.

Cluster analysis was performed to determine the season with the most negative upwelling indices. A linkage function based on the shortest distance algorithm was considered to compute the hierarchical cluster tree. The histogram (Fig. 2), corresponding to the appearance of each month on the most negative partition (more intense upwelling) of the dendrogram, shows the very frequent occurrence of upwelling events during the period from July to October. From the 21 available years, favourable conditions for upwelling were observed 15 times in July, 20 in August, 18 in September and 12 in October.

\subsection{Atmospheric data processing}

The teleconnection indices for the NAO, EA, SCA, EA/WR and POL were obtained from the Climate Prediction Center (CPC) at the NCEP (www.cpc.noaa.gov) at monthly time scales from 1950 to 2005. Rotated principal component analysis (RPCA) was used to identify the Northern Hemisphere teleconnection patterns and indices (Barnston \& Livezey 1987). This procedure isolates the primary teleconnection patterns for all months and allows time series of the patterns to be constructed. The RPCA technique is applied to monthly mean standardized $500 \mathrm{mb}$ height anomalies obtained from the NASA's Coordinated Data Analysis System (CDAS) in the analysis region $\left(20\right.$ to $\left.90^{\circ} \mathrm{N}\right)$. For

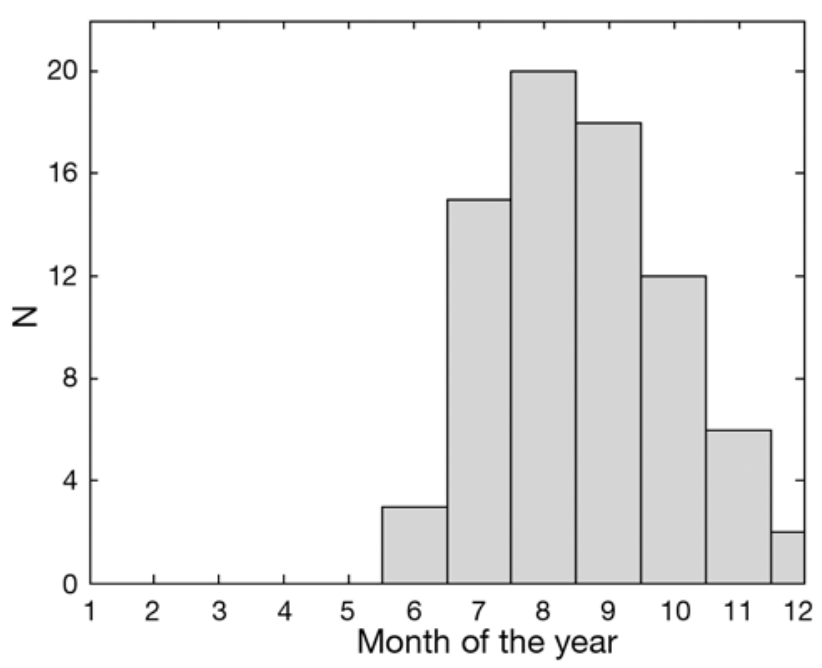

Fig. 2. Cluster analysis of months according to the measured upwelling index from 1985 to 2005. N: number of times that a month is under the most upwelling-favourable conditions (the most negative part of the distribution) 
each calendar month, the 10 leading unrotated EOFs (empirical orthogonal functions) are first determined from the standardized monthly height anomaly fields in the 3 mo period centred on that month (i.e. the July pattern is calculated based on the June through August monthly standardized anomaly fields). A varimax rotation is then applied to these 10 leading unrotated modes, yielding the 10 leading rotated modes and their time series for that calendar month. In the varimax rotation technique (Kaiser 1958), the indices for the 10 leading rotated modes are calculated simultaneously for each month in the record using a least squares solution. These indices are the solution to the least squares system of equations, and reflect the combination of modes that explains the most spatial variance of the observed standardized height anomaly field in that month.

An examination of all 12 sets of rotated modes revealed 10 dominant teleconnection patterns, of which 8 to 9 appear in each of the 12 calendar months. These patterns are referred to as the NAO, the Pacific/North American teleconnection pattern, the EA, the West Pacific pattern, the East Pacific-North Pacific pattern, the EA/WR, the Tropical/Northern Hemisphere pattern, the Polar-Eurasian pattern, the SCA and the Pacific Transition pattern. From these 10 dominant teleconnection patterns only the 5 described earlier in the introduction are shown to be representative of the North Atlantic region. Correlations between atmospheric modes (EA, POL, SCA, NAO and EA/WR) were performed without any significance, both during the period of time under study (from 1985 to 2005) and during the period of time for which data are available (from 1950 to 2005).

SLP data were obtained from reanalysis data from a cooperating project between the NCEP and the NCAR (www.cdc.noaa.gov/cdc/reanalysis/reanalysis. shtml). The goal of this joint effort is to produce new atmospheric analyses using historical data (1948 onwards), as well as to produce analyses of the current atmospheric state (CDAS). This effort involves: (1) the recovery of land surface, ship, rawinsonde, pibal, aircraft, satellite and other data and (2) quality controlling and assimilating these data with a data assimilation system, which is kept unchanged over the reanalysis period. This eliminates perceived climate jumps associated with changes in the data assimilation system. The data are defined on $90^{\circ} \mathrm{N}$ to $90^{\circ} \mathrm{S}, 0$ to $357.5^{\circ} \mathrm{E}$, with a spatial resolution of $2.5 \times 2.5^{\circ}$. Daily data from 1985 to 2005 on a 20 to $60^{\circ} \mathrm{N}, 30^{\circ} \mathrm{W}$ to $5^{\circ} \mathrm{E}$ grid were selected for the present study.

Monthly zonal Ekman transport $\left(Q_{X}\right)$ values were retrieved from the NOAA Fisheries Service Environmental Reseach Division (http://las.pfeg.noaa.gov). Data were collected from 1967 to 2005 at $10.5^{\circ} \mathrm{W}$ from
37. 5 to $41.5^{\circ} \mathrm{N}$, with a grid mesh of $1^{\circ}$. These data cover the western coast of the IP. Offshore Ekman transport (negative $Q_{X}$ ) corresponds to conditions favourable for upwelling.

\section{RESULTS AND DISCUSSION}

\subsection{Characterization of SST and UI variability}

The monthly variability of the SST field can be observed in Fig. 3 by means of the 21 yr mean SST fields for each month. For the sake of comparison the thermal amplitude in each snapshot is $4^{\circ} \mathrm{C}$, although it is centred on different values to cover the annual cycle. There is a high latitudinal increase in temperature $\left(4\right.$ to $5^{\circ} \mathrm{C}$ from 37 to $43^{\circ} \mathrm{N}$ ) from December to May due to the different solar irradiance. This temperature increment decreases from June to November, reaching a minimum value of $2{ }^{\circ} \mathrm{C}$ from July to September, when a longitudinal gradient in SST develops. A decrease in near shore temperature is observed when colder subsurface water upwells to replace warmer surface waters driven away from the coast by wind and Coriolis effects. The difference in temperature between 7 and $12^{\circ} \mathrm{W}$ reaches a maximum value of $3^{\circ} \mathrm{C}$ in August and September; it is almost negligible from December to May.

Upwelling evolution from 1985 to 2005 along the IP coast is shown in Fig. 4. The density plot in Fig. 4a shows the annual periodicity of the anomaly upwelling index signal $(\mathrm{UIn}=\mathrm{UI}-<\mathrm{UI}>$, where $<\mathrm{UI}>$ is the mean upwelling index in time and space) along the western coast of the IP. This upwelling index anomaly was used to enhance the differences between favourable (negative indices) and unfavourable (positive indices) upwelling conditions.

The meridional annual cycle can be determined by averaging UIn in time from 1985 to $2005\left(<\mathrm{UIn}>_{t}\right)$ (Fig. 4b). Negative values were observed from July to October (upwelling season), with the strongest negative values observed at latitudes from 42 to $43^{\circ} \mathrm{N}$ due to topography-induced upwelling (Torres et al. 2003). The existence of an upwelling season during summer associated with persistent northerly winds blowing along the shelf is consistent with previous research (Alvarez et al. 2005, Santos et al. 2005, Gómez-Gesteira et al. 2006). Positive values (unfavourable upwelling conditions) were detected along the entire coast from January to May, with the strongest positive values between latitudes 42 and $43^{\circ} \mathrm{N}$ from January to April and between latitudes 40 and $41.5^{\circ} \mathrm{N}$ during April.

Once the annual cycle has been determined, interannual differences can be established by averaging UIn from 37 to $43^{\circ} \mathrm{N}\left(<\mathrm{UIn}>_{\text {lat }}\right)$ (Fig. 4c). This meridional averaging could be a source of errors in areas 

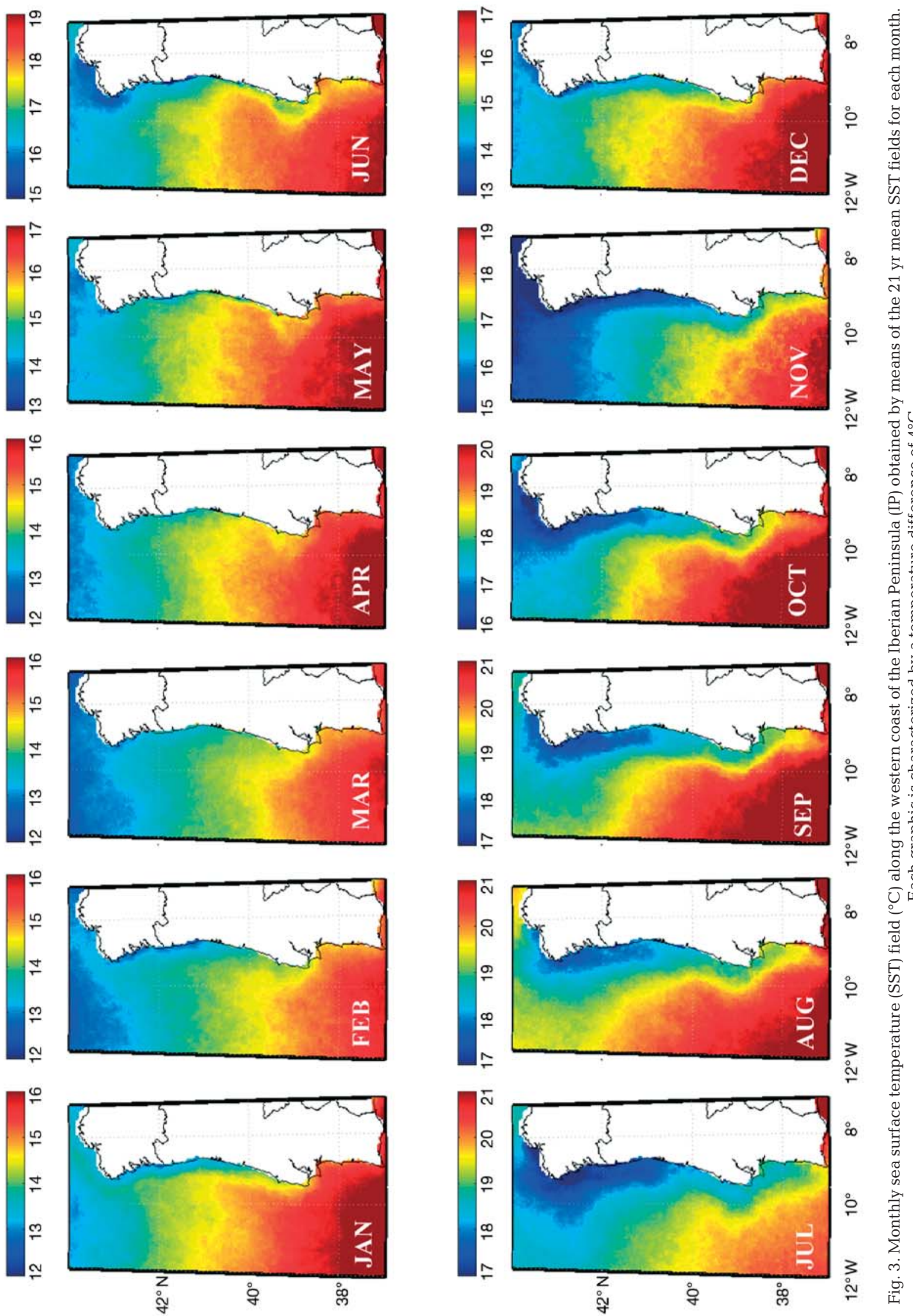

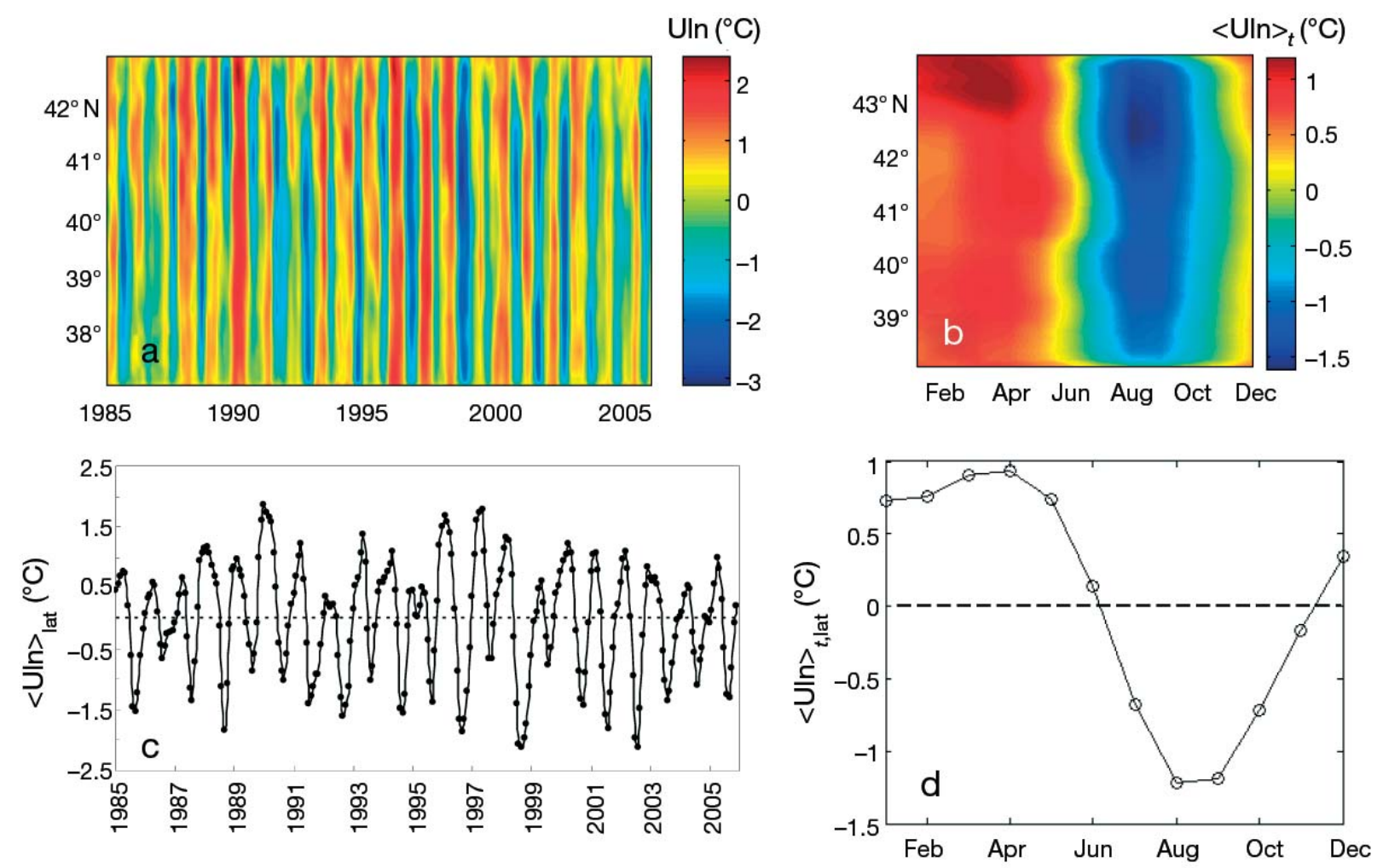

Fig. 4. (a) Inter-annual evolution of the normalized upwelling index (UIn, ${ }^{\circ} \mathrm{C}$ ), from 1985 to 2005. (b) The 21 yr (1985 to 2005 ) mean of the annual evolution of UIn $\left(<\mathrm{UIn}>t_{1}{ }^{\circ} \mathrm{C}\right)$. (c) Inter-annual evolution of the meridional average of UIn from 1985 to $2005\left(<\mathrm{UIn}>_{\text {lat }}{ }^{\circ} \mathrm{C}\right)$.

(d) Meridional and time average of UIn $\left(<\mathrm{UIn}>t\right.$, lat, $\left.{ }^{\circ} \mathrm{C}\right)$

with high latitudinal gradients. However, previous snapshots only show a slight dependence on latitude. The signal from 1985 to 2005 is irregular, showing years with a strong upwelling season characterized by values between -2 and $-2.5^{\circ} \mathrm{C}$ (e.g. 1988, 1996, 1998, 2001 and 2002) and years with a weak upwelling season characterized by values that do not surpass $-1{ }^{\circ} \mathrm{C}$ (e.g. 1986, 1997 and 1999). The signal does not show any clear trend indicative of weakening or strengthening of upwelling during the last 2 decades.

The meridional and time averaging $(<\mathrm{UIn}\rangle_{t}$, lat $)$ shows the global behaviour of the area under discussion (Fig. 4d). Positive values were observed from December to May, with the maximum value close to $1^{\circ} \mathrm{C}$ during March and April. Negative values were observed from July to October, reaching values close to $-1.5^{\circ} \mathrm{C}$ during August and September. Values near $0^{\circ} \mathrm{C}$ were observed during June and November, which can be considered transition months. A similar behaviour was also observed in the seasonal variability of the zonal Ekman transport $\left(Q_{X}\right)$ calculated from 1966 to 2005 by Cabanas \& Alvarez (2005) at $43^{\circ} \mathrm{N}, 11^{\circ} \mathrm{W}$. In this case, the $Q_{X}$ component shows the highest values in December to January and the lowest ones in July to August, corresponding with the upwelling season. Both the UI calculated using SST and the $Q_{X}$ values obtained from wind fields were spatially averaged along the western coast of the IP before being compared. The correlation between both data series is depicted in Fig. 5 at different lag intervals. The best correlation is observed when UI lags $Q_{X}$ by 1 or 2 mo. This lag had previously been noted by Nykjaer \& Van Camp (1994). In addition, Fiuza et al. (1982) observed a similar lag off Portugal.

\subsection{Effect of atmospheric variability on upwelling}

According to the results shown in the previous figures (Figs. 2 to 4 ), the JASO period of time corresponds to the upwelling season. Data from this season were selected so as to analyze the influence of the most representative regional patterns of atmospheric variation (NAO, EA, SCA, EA/WR and POL) on the inter-annual evolution of coastal upwelling events from 1985 to 2005. The inter-annual trends between monthly teleconnection indices and UI anomalies (UIA) were compared using a $t$-test (significant at the $90 \%$ level). The monthly UIA was calculated according to the expression $\operatorname{UIA}(m)=\mathrm{UI}(m)-\langle\mathrm{UI}\rangle_{m}$, where $m$ refers to the month and $\langle\mathrm{UI}\rangle_{m}$ is the mean of the UI for month $m$ from 1985 to 2005 . 


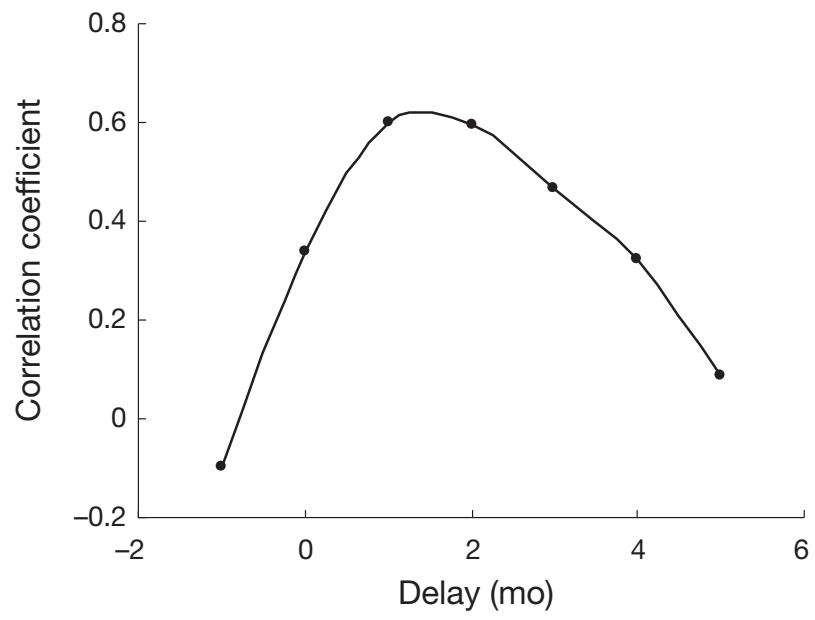

Fig. 5. Correlation between the SST-dependent upwelling index and zonal Ekman transport $\left(Q_{X}\right)$ from 1985 to 2005. The best correlation between both series is observed when UI lags $Q_{x}$ by 1 or $2 \mathrm{mo}$, with a significance level $>99 \%$

Only 2 modes (EA and NAO) showed a non-negligible influence on UIA (Fig. 6). In both cases, solid circles indicate a significance level $>90 \%$. The main upwelling variability along the western coast of the IP can be explained in terms of the EA pattern, showing a significant negative correlation along the entire coast (Fig. 6, black line). The correlation coefficient increases from -0.4 at $37^{\circ} \mathrm{N}$ to -0.5 around $38^{\circ} \mathrm{N}$, then, continuously weakens towards $41^{\circ} \mathrm{N}$, with values close to -0.25 . Values between -0.35 and -0.3 are observed northward. The NAO pattern is the second atmospheric mode with some influence on UIA variability (Fig. 6, grey line), showing a significant positive correlation between 38 and $41^{\circ} \mathrm{N}$, where it reaches values close to 0.4 . The rest of the atmospheric modes did not show a significant influence on UIA along the western coast of the IP during the upwelling season. On average, the most prominent mode (EA) is on the order of -0.4 , which constitutes a significant, but not very high

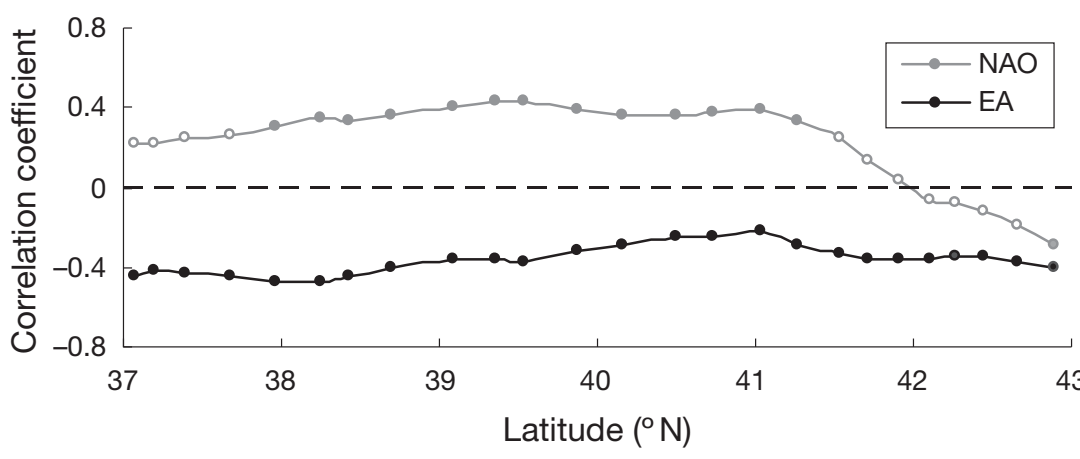

Fig. 6. Meridional variability of the correlation coefficient between the JASO (July to October) UIA and the JASO EA (East Atlantic pattern, black line) and between JASO UIA and the JASO NAO (North Atlantic Oscillation, grey line), yearly averaged from 1985 to 2005. Full (empty) circles correspond to a significance above (below) $90 \%$ in the $t$-test correlation. This value is considerably lower than the one obtained by deCastro et al. (2008) when analyzing the correlation between Ekman transport and the atmospheric modes along the western coast of Galicia during the wet season (NDJF) from 1966 to 2005. These authors found that EA was the most prevalent mode, with a correlation on the order of 0.6. The main cause of the difference in correlation coefficient possibly comes from the high variability observed in upwelling conditions during the wet season compared to the lower variability observed during the dry season (Gómez-Gesteira et al. 2006).

UIA was averaged from 37 to $43^{\circ} \mathrm{N}$ (UIAM), and it was correlated with the EA pattern during the upwelling season (Fig. 7a). This figure shows a negative correlation between EA (solid line) and UIAM (dashed line), with both variables following opposite patterns from 1985 to 1990 and from 1994 to 2005. From 1990 to 1994 both variables follow a similar pattern. This negative correlation between both variables can also be observed in the scatter plot shown in Fig. $7 \mathrm{~b}$, where $>75 \%$ of the points lie in the fourth quadrant.

The previous correlation analysis can only be considered as an exploratory way to show that UIA can be influenced by the EA atmospheric mode. Three methods have been considered to give a physical interpretation to those correlations: (1) analysis of extreme events, (2) analysis of SLP composite and (3) analysis of zonal Ekman transport. Nine months with extreme negative values of UIAM were selected during the upwelling season from 1985 to 2005 (Table 1). These months represent $10 \%$ of the upwelling events during the period of time under study. All of them correspond to well-developed upwelling conditions with UIAM values below $-1.85^{\circ} \mathrm{C}$. The EA phase during those months was positive in 8 cases (almost $90 \%$ of the available cases). In addition, SLP composites were analyzed during the upwelling season. Two SLP composites were calculated for months under the most favourable upwelling conditions (UIA $(\mathrm{m}) \leq\langle\mathrm{UIA}\rangle-0.5 \sigma(\mathrm{UIA})$ ) see Fig. 8a) and for months under the least favourable upwelling conditions (UIA $(m) \geq\langle U I A\rangle-0.5 \sigma(U I A)$, see Fig. 8b). $<$ UIA $>$ is the mean upwelling index anomaly averaged during the upwelling season (JASO) from 1985 to 2005, and $\sigma$ (UIA) is the standard deviation calculated during the same period. Fig. 8a and b show a high pressure centre located in front of the western coast of the IP at $35^{\circ} \mathrm{N}, 35^{\circ} \mathrm{W}$. This centre produces northerly winds blowing along the shelf with strong intensity during months with strong negative values of UIA (Fig. 8a) and with weak intensity 

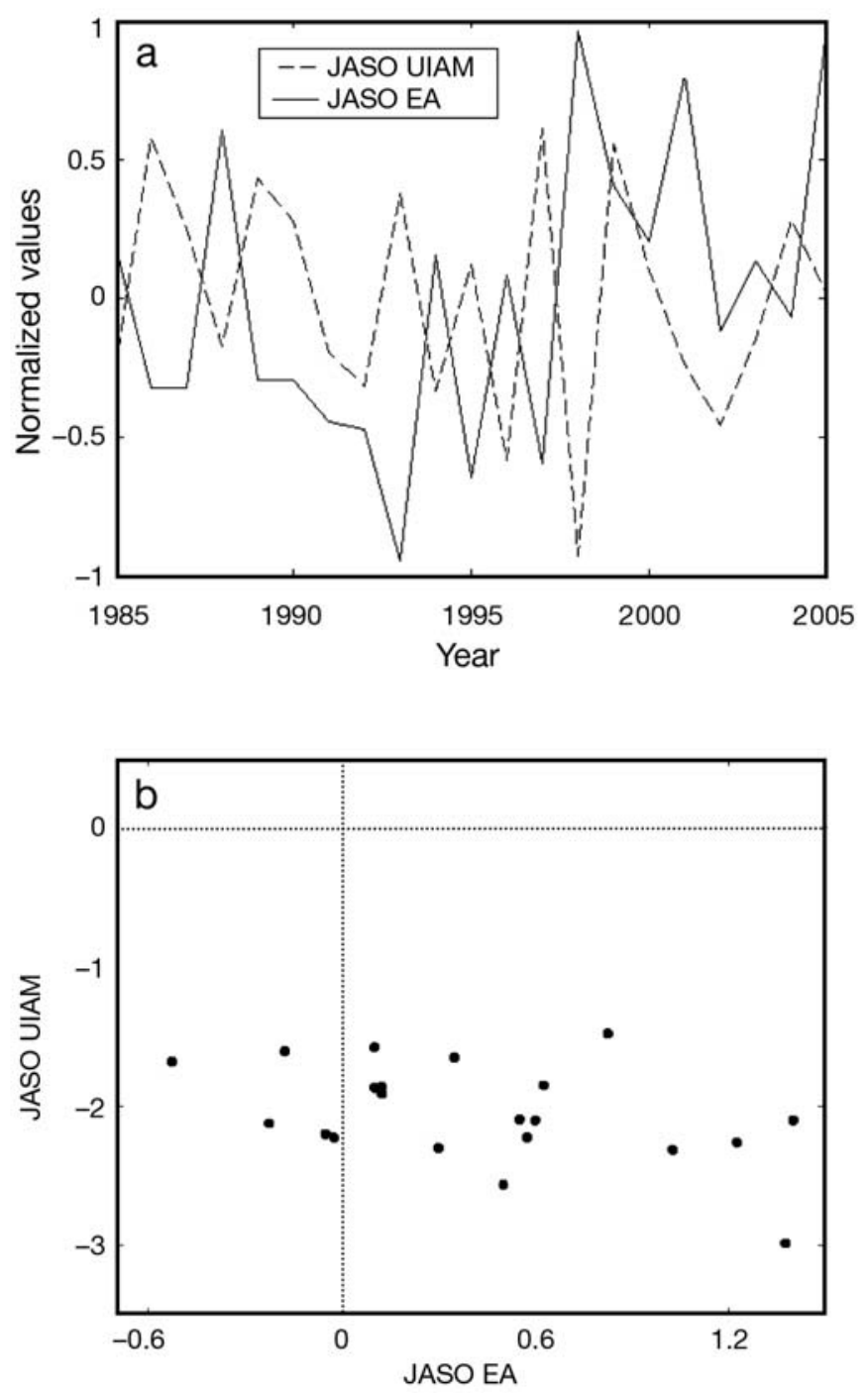

Fig. 7. (a) Inter-annual variation of JASO EA atmospheric circulation pattern (solid line) and JASO UIAM (dashed line) from 1985 to 2005. (b) Scatter plot for the same variables

Table 1. Nine extreme negative UIAM $\left({ }^{\circ} \mathrm{C}\right)$ values observed during the upwelling season (JASO) from 1985 to 2005, and the corresponding EA (East Atlantic pattern) value

\begin{tabular}{|lcc|}
\hline Dates & UIAM $\left({ }^{\circ} \mathrm{C}\right)$ & EA \\
\hline Sep 1988 & -2.23 & 0.7 \\
Sep 1994 & -2.52 & -0.5 \\
Aug 1996 & -1.89 & 0.6 \\
Aug 1998 & -2.29 & 2 \\
Sep 1998 & -2.06 & 0.4 \\
Oct 1998 & -1.97 & 1.2 \\
Aug 2001 & -2.07 & 2.6 \\
Aug 2002 & -2.76 & 0.2 \\
Sep 2005 & -2.08 & 1.7 \\
\hline
\end{tabular}


Fig. 8. Sea level pressure (SLP) composites corresponding to the upwelling season (JASO). (a) SLP composite for months, $m$, under the most favourable upwelling conditions (UIA $(m) \leq\langle$ UIA $\rangle-0.5 \sigma(\mathrm{UIA})$ ). (b) SLP composite for months under the least favourable upwelling conditions $(\mathrm{UIA}(\mathrm{m}) \geq$ $\langle$ UIA $\rangle+0.5 \sigma($ UIA $))$. $\langle$ UIA $>$ : mean upwelling index anomaly averaged during the upwelling season (JASO) from 1985 to 2005; $\sigma$ (UIA): standard deviation. (c) SLP composite difference calculated as the difference of Composites a and b. Contour label units: pressure increment from atmospheric pressure (mbar) 
during months with small negative values of UIA (Fig. 8b). Northerly winds blowing along the shelf are favourable conditions for coastal upwelling events along the entire western coast of the IP, in such a way that the situation shown in both composites is always favourable for upwelling although with differing intensity. The difference of previous SLP composites (pattern in Fig. 8a minus the pattern in Fig. 8b) strongly resembles the EA dipole, but with the anomaly centres inverted (Fig. 8c) (see www.cpc.noaa.gov/data/teledoc/ ea.shtml for a full description of EA pattern). The high pressure centre is located near $50^{\circ} \mathrm{N}, 15$ to $25^{\circ} \mathrm{W}$, and the low pressure one, near $25^{\circ} \mathrm{N}, 0^{\circ} \mathrm{W}$. This composite explains the negative correlation between EA and UIA.

The dependence of the upwelling regime on the EA pattern is corroborated by zonal Ekman transport $\left(Q_{X}\right)$ analysis (Fig. 9) following the protocol described in Fig. 6. Fig. 9 shows a significant negative correlation between $Q_{X}$ and EA along the entire coast during the upwelling season. The correlation is observed to decrease northward.

\section{SUMMARY AND CONCLUSIONS}

Coastal areas are of large economic and ecologic importance. Around $20 \%$ of the global fish catch is obtained in near shore regions, especially in those areas affected by coastal upwelling events. Upwelling shows a marked periodicity, but with important inter-annual changes, which are due, among other factors, to changes in atmospheric regime. Thus, the predictability of upwelling events is a challenge to the scientific community in the context of optimising fishing activities. The correlation between atmospheric patterns and upwelling indices constitutes a first step to better understand the external influences in upwelling and its predictability.

The western coast of the IP is part of the CUE, which is 1 of the 4 major eastern boundary upwelling regions

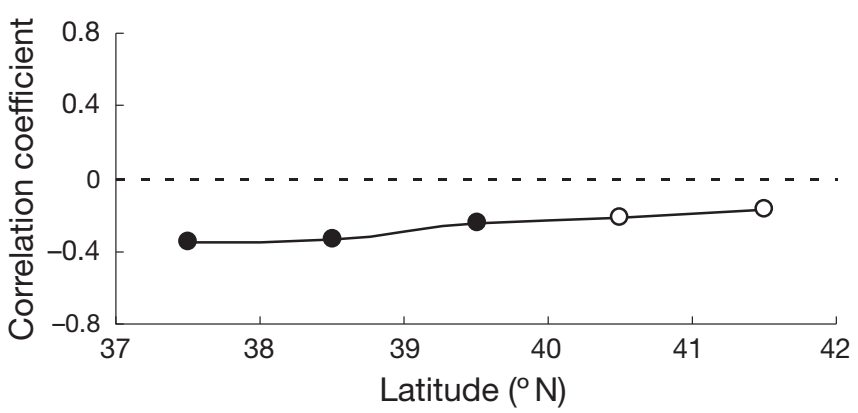

Fig. 9. Meridional variability of the correlation coefficient between zonal Ekman transport $\left(Q_{X}\right)$ and EA during the upwelling season (JJAS) from 1967 to 2005. Full (empty) circles correspond to a significance level above (below) $90 \%$ in the $t$-test in the world. A SST-based upwelling index was defined to characterize upwelling variability from 1985 to 2005, reproducing the well known annual variability along the western IP coast and showing an upwelling season from July to October. This season has a 2 mo lag with respect to the wind-based upwelling season, as previously noted by Nykjaer \& Van Camp (1994).

Upwelling is shown to be more intense in the area between 41 and $42.5^{\circ} \mathrm{N}$, where coastal upwelling is reinforced by topography according to Torres et al. (2003) and Santos et al. (2005). During the period from 1985 to 2005 , the strongest events took place in 1988 , 1996, 1998, 2001 and 2002 and the weakest in 1986, 1997 and 1999.

The influence of NAO, EA, SCA, EA/WR and POL on coastal upwelling was analyzed during the upwelling season (JASO). Results show that the main upwelling variability can be explained in terms of the EA pattern, with a significant negative correlation along the entire coast. The NAO pattern is the second most influential atmospheric mode with some influence on upwelling variability, showing a significant positive correlation only between 38 and $41^{\circ} \mathrm{N}$. The rest of the atmospheric modes did not show any significant influence on upwelling variability.

The dependence of the upwelling regime on the EA pattern is corroborated by 3 independent techniques: analysis of extreme events, analysis of the SLP composite and analysis of zonal Ekman transport.

The EA influence on the area under examination is probably due to the position of the geopotential anomalies of their dipoles during the upwelling season. The SLP composite, calculated as the difference of composites for months with strong upwelling indices and those of composites for months with weak upwelling indices, resembles the EA dipole, but with the anomaly centres inverted. This SLP composite explains the negative sign of the correlation between EA and UIA.

The major implication of this work is the possibility of explaining upwelling variability in the area under examination in terms of a single atmospheric mode (EA), with a little influence from the NAO index and negligible influence from the rest of the Northern Hemisphere modes. However, the correlation with atmospheric indices only provides a descriptive view of the atmosphere-ocean interaction. The use of global atmosphere-ocean models could be a useful tool to provide a more mechanistic picture. Further research should be conducted in this direction.

Acknowledgements. We acknowledge P. Mayes for his kind help with the text editing. This work is supported by the Ministerio de Educacion y Ciencia under projects CTM200762546-C03-03/MAR and CTM2006-05882-C04-03/MAR and by Xunta de Galicia under Projects PGIDIT06PXIB383285PR and PGIDIT06PXIB383288PR. 


\section{LITERATURE CITED}

Alvarez I, deCastro M, Gómez-Gesteira M, Prego R (2005) Inter- and intra-annual analysis of the salinity and temperature evolution in the Galician Rias Baixas-ocean boundary (NW Spain). J Geophys Res 110:C04008

Barnston AG, Livezey RE (1987) Classification, seasonality and persistence of low-frequency atmospheric circulation patterns. Mon Weather Rev 115:1083-1126

Blanton JO, Tenore KR, Castillejo F, Atkinson LP, Schwing FB, Lavín A (1987) The relationship of upwelling to mussel production in the rias of the western coast of Spain. J Mar Res 45:497-511

Bojariu R, Gimeno L (2003) Predictability and numerical modelling of the North Atlantic Oscillation. Earth Sci Rev 63(1):145-168

Brown JW, Brown OB, Evans RH (1993) Calibration of AVHRR infrared channels: a new approach to non-linear correction. J Geophys Res 98(NC10):18257-18268

Cabanas JM, Alvarez I (2005) Ekman transport patterns in the area close to the Galician coast (NW, Spain). J Atmos Ocean Sci 10:325-341

- Czaja A, Marshall J (2002) Observed impact of Atlantic SST anomalies on the North Atlantic Oscillation. J Clim 15: 606-623

deCastro M, Lorenzo N, Taboada JJ, Sarmiento M, Alvarez I, Gómez-Gesteira M (2006) Influence of teleconnection patterns on precipitation variability and on river flow regimes in the Miño River basin (NW Iberian Peninsula). Clim Res 32:63-73

deCastro M, Gómez-Gesteira M, Alvarez I, Lorenzo N, Cabanas JM, Prego R, Crespo AJC (2008) Characterization of fall-winter upwelling recurrence along the Galician western coast (NW Spain) from 2000 to 2005: dependence on atmospheric forcing. J Mar Syst (in press) doi:10.1016/j. jmarsys.2007.04.005

Di Lorenzo E (2003) Seasonal dynamics of the surface circulation in the Southern California Current System. Deep-Sea Res II 50:2371-2388

Fiuza A, Macedo ME, Guerreiro MR (1982) Climatological space and time variation of the Portuguese coastal upwelling. Oceanol Acta 5:31-40

Ginzburg AI, Kostianoy GA, Sheremet NA (2004) Seasonal and interannual variability of the Black Sea surface temperature as revealed from satellite data (1983-2000). J Mar Syst 52:33-50

Gómez-Gesteira M, Moreira C, Alvarez I, deCastro M (2006) Ekman transport along the Galician coast (NW, Spain) calculated from forecasted winds. J Geophys Res 111:C10005

Kaiser HF (1958) The varimax criterion for analytic rotation in factor analysis. Psychometrika 23:187-200

Kapala A, Mächel H, Flohn H (1998) Behaviour of the centres of action above the Atlantic since 1881. II. Associations with regional climate anomalies. Int J Climatol 18:23-36

Lorenzo MN, Taboada JJ (2005) Influences of atmospheric variability on freshwater input in Galician Rias in winter. J Atmos Ocean Sci 10:377-387

Lorenzo MN, Taboada JJ, Gimeno L (in press) Links between circulation weather types and teleconnection patterns and their influence on precipitation patterns in Galicia (NW Spain). Int J Climatol. doi:10.1002/joc.1646

Editorial responsibility: Joan Kleypas,

Boulder, Colorado, USA
McClain EP, Pichel WG, Walton CC (1985) Comparative performance of AVHRR based multichannel sea surface temperatures. J Geophys Res 90:11587-11601

> Nykjaer L, Van Camp L (1994) Seasonal and interannual variability of coastal upwelling along northwest Africa and Portugal from 1981 to 1991. J Geophys Res 99: 14197-14208

Pelegri JL, Aristegui J, Cana L, Gonzalez-Davila M and others (2005) Coupling between the open ocean and the coastal upwelling region off northwest Africa: water recirculation and offshore pumping of organic matter. J Mar Syst 54: 3-37

Pozo-Vázquez D, Gámiz-Fortis SR, Tovar-Pescador J, Esteban-Parra MJ, Castro-Díez Y (2005) El Niño-Southern Oscillation events and associated European winter precipitation anomalies. Int J Climatol 25:17-31

Rodó X, Baert E, Comin FA (1997) Variations in seasonal rainfall in southern Europe during the present century: relationships with the North Atlantic Oscillation and the El Niño-Southern Oscillation. Clim Dyn 13:275-284

Rodríguez-Puebla C, Encinas $\mathrm{AH}$, Nieto S, Garmendia J (1998) Spatial and temporal patterns of annual precipitation variability over the Iberian Peninsula. Int J Climatol 18:299-316

Rodríguez-Puebla C, Encinas AH, Sáenz J (2001) Winter precipitation over the Iberian Peninsula and its relationship to circulation indices. Hydrol Earth Syst Sci 5:233-244

Saenz J, Zubillaga J, Rodríguez-Puebla C (2001) Interannual winter temperature variability in the north of the Iberian Peninsula. Clim Res 16:169-179

Santos AMP, Kazmin AS, Peliz A (2005) Decadal changes in the Canary upwelling system as revealed by satellite observations: their impact on productivity. J Mar Res 63: 359-379

Shannon LJ, Moloney CL, Jarre A, Field JG (2003) Trophic flows in the southern Benguela during the 1980s and 1990s. J Mar Syst 39:83-116

Slonosky V, Yiou P (2002) Does the NAO index represent a zonal flow? The influence of the NAO on North Atlantic surface temperature. Clim Dyn 19:17-30

Tang DL, Kawamura H, Guan L (2004) Long-time observation of annual variation of Taiwan Strait upwelling in summer season. Adv Space Res 33:307-312

Thompson DWJ, Wallace JM (2000) Annular modes in the extratropical circulation. I. Month-to-month variability. J Clim 13:1000-1016

Torres R, Barton ED, Miller P, Fanjul E (2003) Spatial patterns of wind and sea surface temperature in the Galician upwelling region. J Geophys Res 108(C4):3130

Trigo RM, Pozo-Vázquez D, Osborn TJ, Castro-Díez Y, Gámiz-Fortis S, Esteban-Parra MJ (2004) North Atlantic Oscillation influence on precipitation, river flow and water resources in the Iberian Peninsula. Int $\mathrm{J}$ Climatol 24: 925-944

Thompson DWJ, Wallace JM (1998) The Arctic Oscillation signature in the wintertime geopotential height and temperature fields. Geophys Res Lett 25:1297-1300

Zavala-Hidalgo J, Gallegos-García A, Martínez-López B, Morey SL, O'Brien JJ (2006) Seasonal upwelling on the western and southern shelves of the Gulf of Mexico. Ocean Dyn 56(3/4): 333-338

Submitted: February 7, 2007; Accepted: February 19, 2008 Proofs received from author(s): April 3, 2008 